\title{
Evaluation of monthly capacity factor of WECS using chronological and probabilistic wind speed data: A case study of Taiwan
}

\author{
Tsang-Jung Chang ${ }^{\mathrm{a}, *}$, Yi-Long $\mathrm{Tu}^{\mathrm{a}, \mathrm{b}}$ \\ ${ }^{a}$ Department of Bioenvironmental Systems Engineering, National Taiwan University, Taipei 106, Taiwan \\ ${ }^{\mathrm{b}}$ Jen-Teh Junior College of Medicine, Nursing and Management, Miaoli 356, Taiwan
}

Received 24 July 2006; accepted 18 October 2006

Available online 12 December 2006

\begin{abstract}
Monthly energy outputs and capacity factors of an existing median-scale wind power station located in Mailiao, Taiwan, have been analyzed by using the measured half-hourly wind speed data over a period spanned between 2002 and 2005. The wind speed data in the chronological (time-series) format and probabilistic (Weibull) format are used to estimate the monthly capacity factors of Vestas V47-660 KW turbines in Mailiao. The monthly capacity factors calculated from the chronological and probabilistic approaches are compared with and validated by the measured capacity factors obtained in Mailiao. In addition, due to the climatic features of the Asia monsoon, there are two prominent wind periods within a year in Taiwan, i.e., the strong (October-March) and weak (April-September) wind periods. This study also investigates the differences of the measured and calculated capacity factors in the strong and weak wind periods of Mailiao. It is shown that the capacity factors calculated from the time-series approach have better agreement with the actual capacity factors than the Weibull approach. Both approaches have slightly underestimated the capacity factors in the strong wind period, but have significantly overestimated the capacity factors in the weak wind period.
\end{abstract}

(C) 2006 Elsevier Ltd. All rights reserved.

Keywords: Monthly capacity factor; Time-series wind speed; Weibull wind speed; Taiwan

\footnotetext{
${ }^{*}$ Corresponding author. Fax: 886223635854.

E-mail address: tjchang@ntu.edu.tw (T.-J. Chang).
} 


\section{Introduction}

Due to the cubic relationship between wind power and wind speed, the wind speed is crucial to evaluate the wind power density and energy output from the wind energy conversion systems (WECS) for a specific site. The wind speed in a selected site is never steady. It is basically influenced by the weather pattern and the local geographical condition, resulting in high temporal variability of wind energy. Among other descending time intervals (minute, hour or day) and ascending time intervals (season or year), wind energy in a monthly interval is the most used information for WECS assessment and installation [1,2]. As a result, a majority of attentions in the past have focused on the accurate estimation methods of the monthly wind power density and monthly energy output from WECS in a specific site [2-14].

Generally, two approaches have been applied. The first approach [2-13] adopts the probabilistic distributions, such as Weibull, Rayleigh, lognormal distributions, etc., to estimate the monthly wind power density and WECS output. This type of approach relies on the appropriate use of the probability density function of wind speed. The parameters of the probability density function are usually determined based on the wind distribution statistics calculated from the measured hourly time-series data. If a wind speed probability distribution and a turbine power (performance) curve are known, energy output from WECS can be obtained. Numerous investigations for different locations around the world have led to the same conclusion that the Weibull distribution gives an excellent fit to the wind speed distributions, and is the most widely used and accepted for estimating the monthly WECS output [1-13]. However, the drawback of the Weibull approach is that there exists more or less differences between the fitted Weibull distribution and time-series data, because no parameter regression process can avoid estimation error.

The second approach [12-15] is using the chronological (time-series) wind speed data to directly investigate the monthly wind power and wind turbine characteristics. Because of the use of original wind speed data, the chronological approach gives more accurate prediction of WECS output than the first approach [12]. Nevertheless, as the aerodynamic performance of a turbine is not of interest to us for the purpose of estimating long-term (yearly or monthly) energy output, taking time average of the measured time series of wind speed and wind turbine power is inevitable. Thus, this type of approach heavily relies on the careful selection of averaging timescales of time-series data, for instance, 10-min, halfhourly, hourly, daily, monthly data, etc. Basically, the energy output calculated by timeseries data with shorter averaging timescale is higher than that by longer averaging timescale [1]. Al-Abbadi [14] estimated the annual energy output of a Nordex N43/600 wind machine by using the 10-min and half-hourly averaged data. The analysis showed that the energy output calculated by 10 -min data is $2.5 \%$ higher than that by half-hourly averaged data. The international energy agency (IEA) has recommended the 10-min averaging time for turbine power performance testing [16]. For the sake of the accuracy of estimating WECS output, the averaging timescale of time-series data should be chosen as close to $10 \mathrm{~min}$ as possible [17]. However, for the reasons of maximizing data collection and minimizing hardware maintenance, many wind power plants use the averaging timescale longer than $10 \mathrm{~min}$. In Taiwan, a half-hourly averaging timescale is mostly adopted in wind speed and power output records of wind power plants.

Among the aforementioned wind energy researches, only few academic works have linked the above two approaches and compared with each other [12,13]. Celik [12] used the 
wind speed data in the hourly time-series format and the Weibull-representative wind speed data to calculate the wind energy output of a small-scale ( $50 \mathrm{~W}$ nominal power) turbine. It is concluded that the Weibull-representative data accurately estimates the wind energy output. The overall error in estimation of monthly energy outputs for the total 96 months of data is only $2.8 \%$. Castro and Ferreira [13] compared these two approaches for estimating wind power capacity factors at peak-load hours. It is shown that the probabilistic approach is a helpful tool to assist WECS planners, whereas the chronological method is best designed to assist WECS operators. However, no research has compared the estimated energy output using the above two approaches to the measured energy output of an existing wind power station.

Due to the lack of academic work that compares the differences of the measured and calculated capacity factors of WECS, the main objective of this research is to further explore the advantages and drawbacks of using these two approaches for estimating capacity factors of WECS. An existing median-scale wind power station, located in Mailiao, Taiwan, is selected as the study site. Four pitch-controlled turbines (Vestas V47$660 \mathrm{KW}$ ) are installed in Mailiao, in which the wind speeds and power outputs are recorded every half an hour. In addition, because of the climatic features of the Asia monsoon, there are two prominent wind periods within a year in Taiwan, i.e., the strong (October-March) and weak (April-September) wind periods. This study also investigates the differences of the measured and calculated capacity factors of WECS in the strong and weak wind periods.

\section{Mathematical formulation}

The wind energy output from WECS for a specific site can be calculated by combining the power curve of the WECS together with the chronological wind speed data or the Weibull wind speed distribution. The mathematical formulation of the chronological wind speed data method and the Weibull distribution method are introduced in the following.

\subsection{Chronological (time series) approach}

The chronological (time series) approach is to use a time-series of wind speed as a basis to calculate energy output from WECS. This approach needs to incorporate the time-series wind speed data into the turbine power curve, as shown in Eq. (1), to estimate the wind energy output from WECS:

$$
P_{i}(V)= \begin{cases}0, & V<V_{\mathrm{I}}, \\ \left(a_{1} V^{3}+a_{2} V^{2}+a_{3} V+a_{4}\right) P_{\mathrm{R}}, & V_{\mathrm{I}} \leqslant V<V_{\mathrm{R}}, \\ P_{\mathrm{R}}, & V_{\mathrm{R}} \leqslant V<V_{\mathrm{O}}, \\ 0, & V \geqslant V_{\mathrm{O}},\end{cases}
$$

where $a_{1}, a_{2}, a_{3}$ and $a_{4}$ are regression constants of the turbine power curve. The wind turbine would operate at constant power with the maximum efficiency between the rated speed $V_{\mathrm{R}}$ and the cut-off speed $V_{\mathrm{O}}$ and at increasing power between the cut-in speed $V_{\mathrm{I}}$ and the rated speed. The wind turbine would stop when the wind speed increases to the cut-off speed $V_{\mathrm{O}}$. In the present study, taking the Vestas V47-660 KW turbine as 
an example, the rate power $P_{\mathrm{R}}$ is $660 \mathrm{KW}$. This turbine has a rotor diameter of $47 \mathrm{~m}$ (the blade sweep area $A=1735 \mathrm{~m}^{2}$ ) and a hub height of $45 \mathrm{~m}$. The cut-in, rated, and cutoff speeds are 4,15 , and $25 \mathrm{~m} / \mathrm{s}$, respectively. The regressed values of $a_{1}, a_{2}, a_{3}$, and $a_{4}$ in Eq. (1) are $-0.00169,0.04446,-0.24764$, and 0.39209 , respectively [2].

Inputting the time-series wind speed data into Eq. (1) and accumulating the entire energy output within one month, the monthly energy output from WECS can be estimated by Eq. (2)

$$
E_{\mathrm{C}}=\sum_{i=1}^{N} P_{i}(V) \Delta t_{i},
$$

where $N$ is 1440 for a half-hourly time-series interval in a month duration $\left(\Delta t_{i}=0.5 \mathrm{~h}\right)$.

The capacity factor is defined to compare the power production of a turbine over a given duration with the amount of power of the turbine operated at the maximum output $100 \%$ of the same amount of duration [1]. A wind turbine operating with the full capacity for a duration $T$ can produce the following rated wind energy:

$$
E_{\mathrm{R}}=T P_{\mathrm{R}}
$$

Thus, the capacity factor can be obtained by

$$
C_{\mathrm{F}}=\frac{E_{\mathrm{C}}}{E_{\mathrm{R}}}
$$

\subsection{Weibull distribution approach}

If a wind speed probability distribution and a turbine power curve are given, the energy output from WECS can be obtained. There are several probability distribution functions that can be used in wind power studies. The Weibull and Rayleigh probability density functions are commonly used and widely adopted [1,2]. Herein the Weibull distribution is used since the Rayleigh distribution is only a subset of it. The Weibull probability density function is a special case of a generalized two parameter gamma distribution. The Weibull distribution can be characterized by its probability density function $f(V)$ and cumulative distribution function $F(V)$ in the following formula:

$$
f(V)=\frac{k}{c}\left(\frac{V}{c}\right)^{k-1} \mathrm{e}^{-(V / c)^{k}}
$$

and

$$
F(V)=1-\mathrm{e}^{-(V / c)^{k}}
$$

where $c$ is the scale parameter, $k$ is the shape parameter, and $V$ is wind speed. In the present study, the scale and shape parameters are estimated by using the maximum likelihood method [2].

Combining Eqs. (1) and (5) yields the estimated wind energy output from a wind turbine in Eq. (7), which is the output electrical power at each wind speed $P_{i}(V)$ multiplied by the 
probability of the wind speed $f(V)$ and integrated over all possible wind speeds:

$$
\begin{aligned}
E_{\mathrm{W}}= & T \int_{V_{\mathrm{I}}}^{V_{\mathrm{O}}} P_{i}(V) f(V) \mathrm{d} V \\
= & T P_{\mathrm{R}} \int_{V_{\mathrm{I}}}^{V_{\mathrm{R}}}\left(a_{1} V^{3}+a_{2} V^{2}+a_{3} V+a_{4}\right) \frac{k}{c}\left(\frac{V}{c}\right)^{k-1} \mathrm{e}^{-(V / c)^{k}} V \\
& +T P_{\mathrm{R}} \int_{V_{\mathrm{R}}}^{V_{\mathrm{O}}} \frac{k}{c}\left(\frac{V}{c}\right)^{k-1} \mathrm{e}^{-(V / c)^{k}} \mathrm{~d} V .
\end{aligned}
$$

The integrals in Eq. (7) are numerically calculated by the six-point Gauss-Legendre quadrature [2].

Dividing the estimated energy output of a wind turbine by the rated wind energy yields the capacity factor as

$$
\begin{aligned}
C_{\mathrm{F}}= & \frac{E_{\mathrm{W}}}{E_{\mathrm{R}}}=\int_{V_{\mathrm{I}}}^{V_{\mathrm{R}}}\left(a_{1} V^{3}+a_{2} V^{2}+a_{3} V+a_{4}\right) \frac{k}{c}\left(\frac{V}{c}\right)^{k-1} \mathrm{e}^{-(V / c)^{k}} \mathrm{~d} V \\
& +\int_{V_{\mathrm{R}}}^{V_{\mathrm{O}}} \frac{k}{c}\left(\frac{V}{c}\right)^{k-1} \mathrm{e}^{-(V / c)^{k}} \mathrm{~d} V .
\end{aligned}
$$

\section{Results and discussion}

An existing median-scale wind power station, located in Mailiao, Yulin County, Taiwan, is taken as the study site. Mailiao is situated in the middle of the west coast of Taiwan. The Mailiao wind power station is the first median-scale wind power station in Taiwan, which is operating with four Vestas V47-660 kW turbines along the coastal line of the Taiwan Strait. It has been starting full operation since December 2000. The wind speeds and power outputs (capacity factors) are recorded every half an hour. In 2001, the first year of operation, the turbine transmission system was out of order frequently, so that the power output records in 2001 were incomplete. Thus, the present study uses the time-series data of wind speed and power output in the years from 2002 to 2005 into the mathematical formulations.

It is important to note that the measured wind speed should avoid interference from the turbine rotor. This ideal situation is difficult to reach and hence some alternative wind speeds are selected instead. The best anemometer location is in 2.5 rotor diameter upstream from the wind turbine [1,16], but setting an anemometer tower in front of the turbine is expensive and would reduce energy production. In Mailiao, the best anemometer location mentioned previously is located in the Taiwan Strait. As a consequence, the anemometer of the Vestas V47-660 KW turbine is mounted on the nacelle cover of the turbine, where is $7 \mathrm{~m}$ behind the blade hub. Thus, the measured wind speed is inevitable affected by the wake of the turbine, resulting in the so-called velocity deficit error. The effect of the velocity-deficit error caused by the poor location of the anemometer on capacity factor estimation is discussed later.

\subsection{Monthly and yearly energy output (capacity factor)}

The capacity factors of the Vestas V47-660 KW turbine from 2002 to 2005 calculated by the chronological approach and the Weibull distribution approach are shown in 
(a)

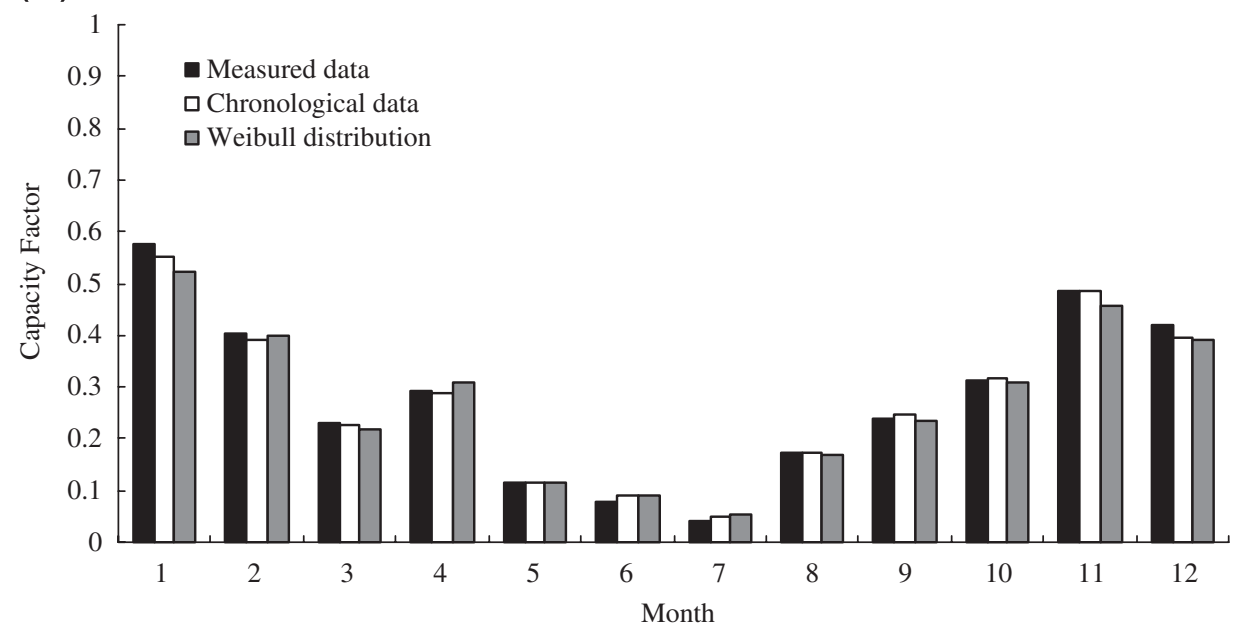

(b)

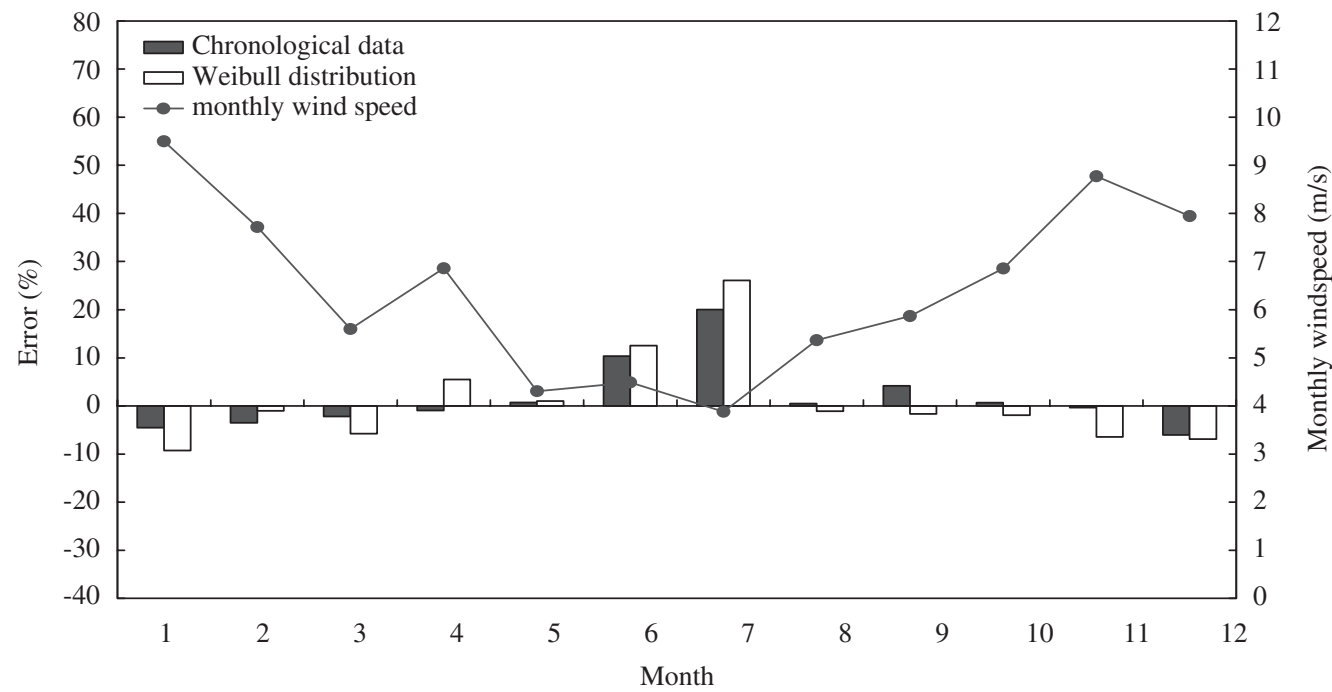

Fig. 1. (a) Comparison of the monthly capacity factors using the chronological approach, the Weibull distribution approach and the actual measurement in 2002. (b) The errors in capacity factor estimation of the two approaches compared to the measured data in 2002.

Figs. 1a to 4a. The measured capacity factors are demonstrated in the above figures as well. For Mailiao, a strong wind period can be observed from October to March, in which the monthly capacity factors are between 0.24 and 0.69 . On the other hand, a weak wind period is from April to September, and its monthly capacity factors are only in the range of 0.03 and 0.29 . The errors in capacity factor estimation calculated by the two approaches are compared with the measured data, which are shown in Figs. 1b to 4b. These figures clearly demonstrate that the estimated monthly capacity factors calculated by the chronological approach are much closer to the four-year measured data in Mailiao. 
(a)

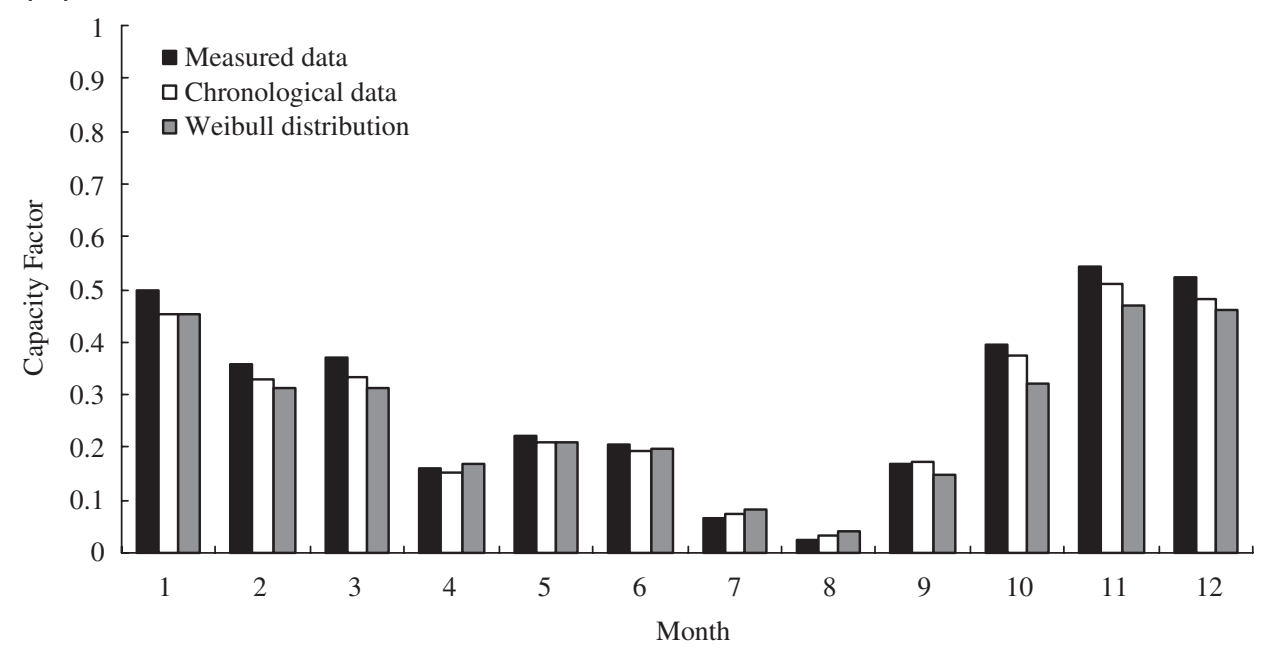

(b)

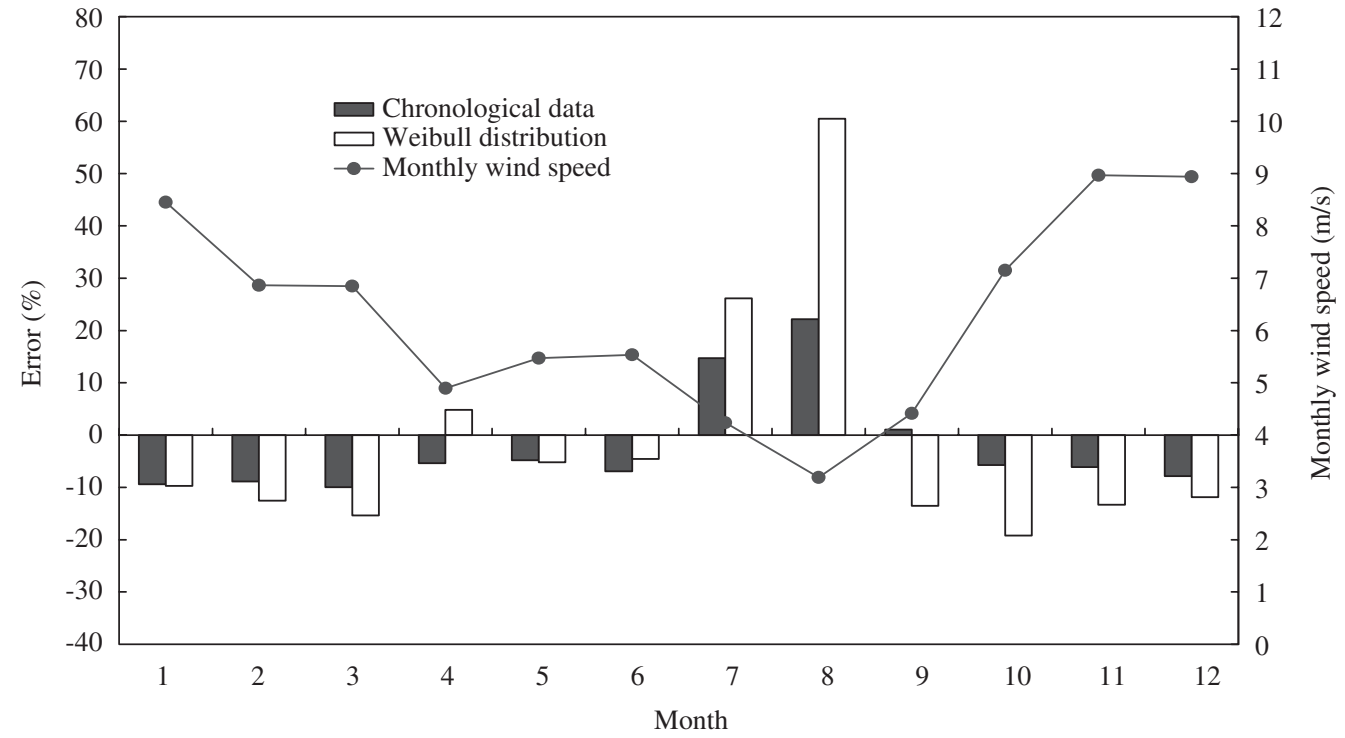

Fig. 2. (a) Comparison of the monthly capacity factors using the chronological approach, the Weibull distribution approach and the actual measurement in 2003. (b) The errors in capacity factor estimation of the two approaches compared to the measured data in 2003.

Based on the monthly errors in capacity factor estimation shown in Figs. 1-4, the yearly average error value (YAEV) of capacity factor estimation is next calculated by the following expression for the purpose of comparing the yearly accuracy of the two approaches:

$$
\operatorname{YAEV}(\%)=\frac{1}{12} \sum_{i=1}^{12}\left|\frac{C_{\mathrm{Fi}}-C_{\mathrm{Fi}, \text { Measured }}}{C_{\mathrm{Fi}, \text { Measured }}}\right|,
$$




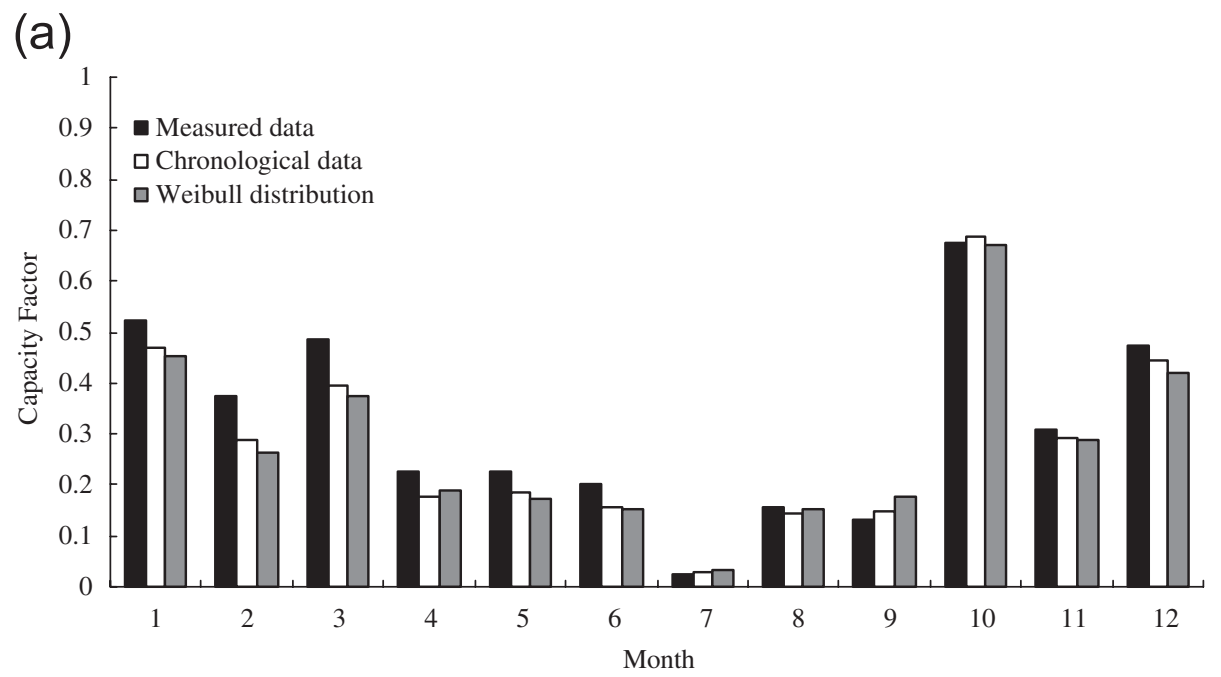

(b)

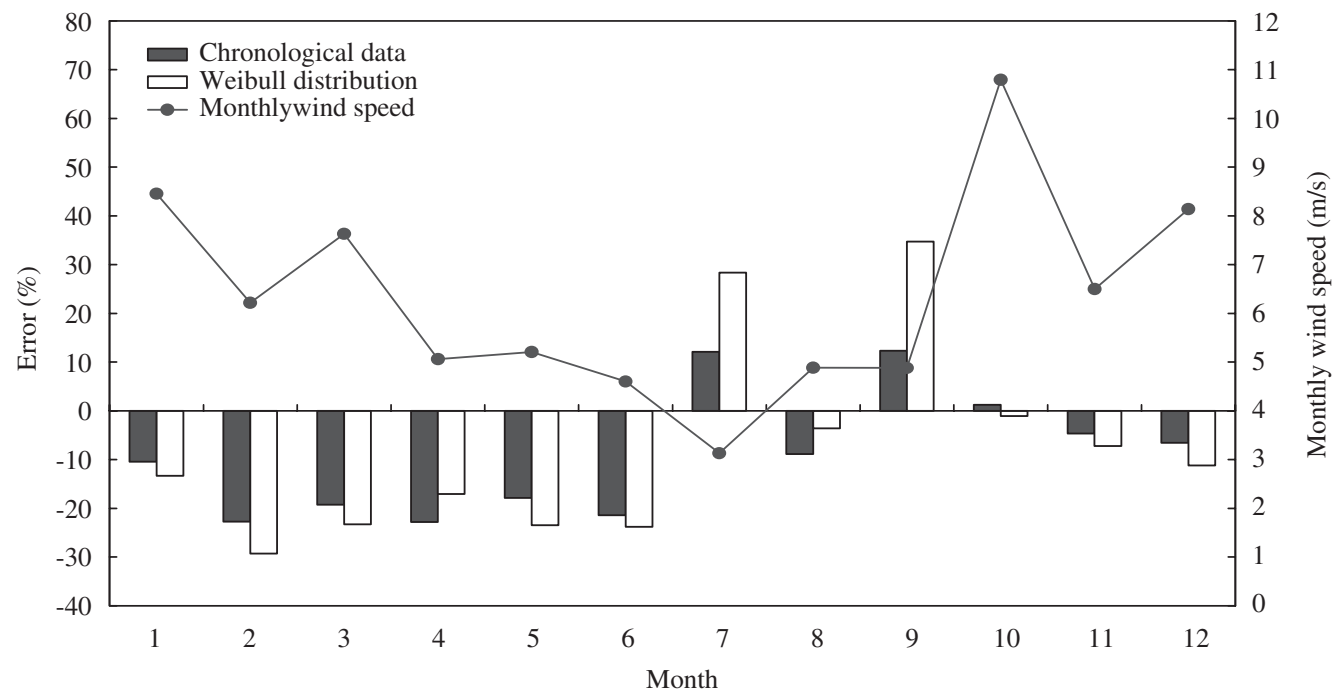

Fig. 3. (a) Comparison of the monthly capacity factors using the chronological approach, the Weibull distribution approach and the actual measurement in 2004. (b) The errors in capacity factor estimation of the two approaches compared to the measured data in 2004.

where $C_{\mathrm{Fi}}$ is the capacity factor calculated by the two approaches for each month, and $C_{\mathrm{Fi}}$, Measured is the measured capacity factor. The YAEV in the years from 2002 to 2005 are demonstrated in Table 1. Both approaches provide acceptable accuracy for estimating capacity factors. The YAEV of the chronological approach ranges from $4.5 \%$ to $13.3 \%$, whereas the YAEV of the Weibull distribution approach is between $6.6 \%$ and $18.0 \%$. The four-year averaged error of the chronological approach is $8.0 \%$, which is much lower than that of the Weibull distribution approach. 


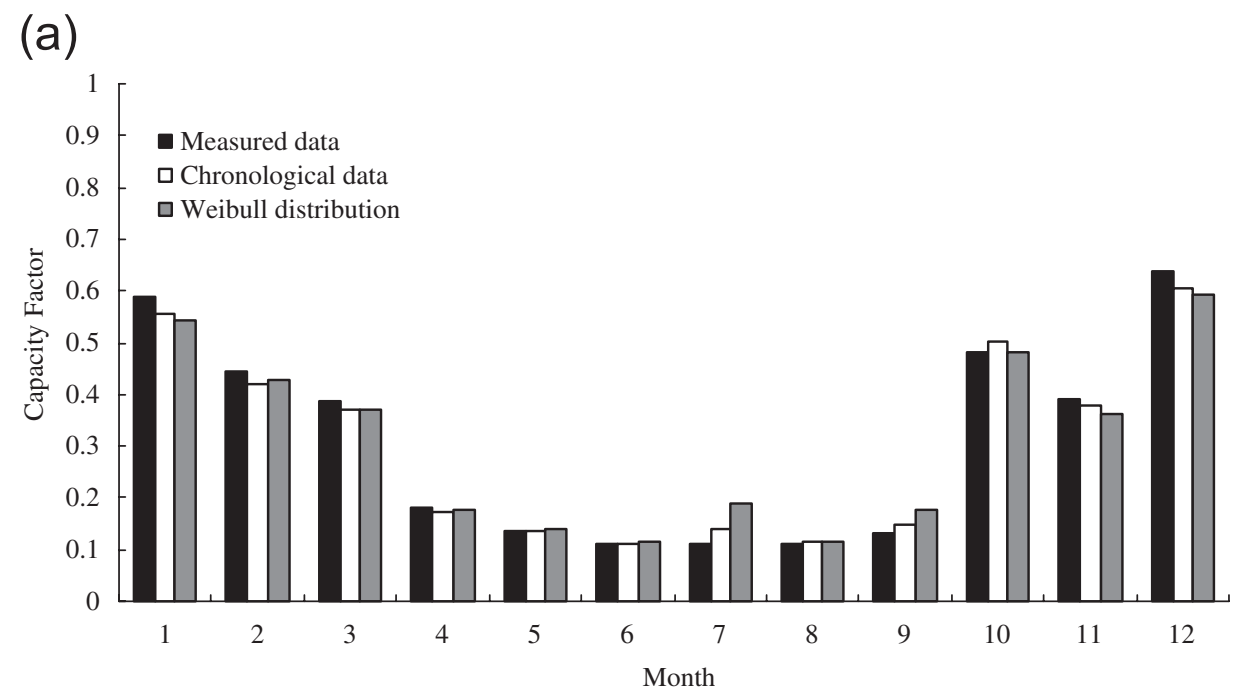

(b)

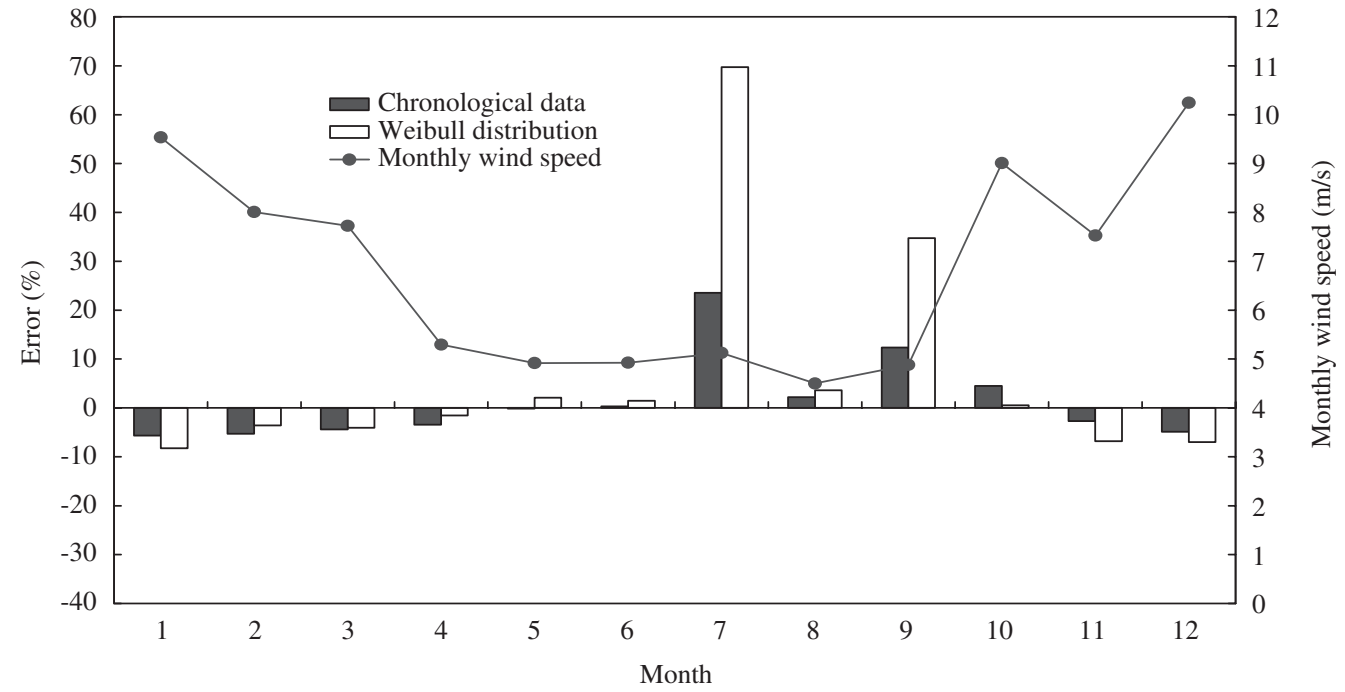

Fig. 4. (a) Comparison of the monthly capacity factors using the chronological approach, the Weibull distribution approach and the actual measurement in 2005. (b) The errors in capacity factor estimation of the two approaches compared to the measured data in 2005.

\subsection{Energy output during strong and weak wind periods}

The wind regime of Taiwan during a year is characterized by the Asia monsoon. The Asia monsoon climate is predominant with strong northeastern trade winds during the period between October and March, whereas southern or southwestern mild winds blow from April to September. As shown in Figs. 1a to 4a, the strong wind period leads to much higher capacity factors than the weak wind period. The results also show that both 
Table 1

Yearly average error value (YAEV) of capacity factor estimation

\begin{tabular}{lcc}
\hline & Chronological approach $(\%)$ & Weibull distribution approach (\%) \\
\hline 2002 & 4.5 & 6.6 \\
2003 & 8.6 & 16.4 \\
2004 & 13.3 & 18.0 \\
2005 & 5.7 & 11.9 \\
Average & 8.0 & 13.2 \\
\hline
\end{tabular}

approaches slightly underestimate the capacity factors in the strong wind period. Since the turbine power curve in Eq. (1) is established based on the 10-min averages of wind speeds and turbine powers, this underestimated error could result from the combined effect of the velocity-deficit error of the anemometer measurement and the error of using half-hourly time-series data.

On the contrary, both approaches significantly overestimate the capacity factors in the weak wind period. To understand the reason causing this overestimated result, the monthly mean wind speed data from 2002 to 2005 is also illustrated in Figs. 1b to 4b for comparison. For the months in which the mean wind speed is very close to the cut-in speed of the Vestas V47-660 KW turbine (4 m/s), such as June and July in 2002, July and August in 2003, July and September in 2004, and July-September in 2005, the monthly capacity factors are apparently overestimated by both approaches. This is because the cut-in speed in the turbine power curve is defined as the lowest speed at which power can be produced. The cut-in speed is basically determined, as is every other point on the turbine power curve, by the 10-min averaging time of the relationship between the wind speed and power output [15]. The use of the lowest speed at which power can be produced as the definition of the cut-in speed in the turbine power curve would result in overestimated power output at low wind speeds. Moreover, some experimental works [18,19] have reported that the starting and low wind speed behavior of wind turbines is quite different from the turbine power curve, and 30-50 s of "idling" periods of slow rotation with little acceleration are observed after the initial start. Thus, for the weak wind period having wind speed as low as the cut-in speed, the two approaches, originally derived from the turbine power curve, give large overestimation on power output.

The present study further investigates the period average error value (PAEV) of capacity factor estimation for the strong and weak wind period, as shown in Table 2. It can be seen from Table 2 that both approaches give much less PAEV in the strong wind period than in the weak wind period.

\subsection{Comparison between the chronological approach and the Weibull distribution approach}

The present study also investigates the differences between the two approaches. Table 3 depicts the yearly and period average error value of capacity factor estimation for the Weibull distribution approach compared to the chronological approach. The result shows that the YAEV of the Weibull distribution approach is between $3.5 \%$ and $8.8 \%$, and the 4-year averaged error value is $6.5 \%$. This result is similar to the research conducted by Celik [12]. In addition, the PAEV for the strong and weak wind periods are in the range of 
Table 2

Period average error value (PAEV) of capacity factor estimation

\begin{tabular}{|c|c|c|c|c|}
\hline & \multicolumn{2}{|c|}{ Strong wind period $(\%)$} & \multicolumn{2}{|c|}{ Weak wind period $(\%)$} \\
\hline & $\begin{array}{l}\text { Chronological } \\
\text { approach }\end{array}$ & $\begin{array}{l}\text { Weibull distribution } \\
\text { approach }\end{array}$ & $\begin{array}{l}\text { Chronological } \\
\text { approach }\end{array}$ & $\begin{array}{l}\text { Weibull distribution } \\
\text { approach }\end{array}$ \\
\hline 2002 & 2.9 & 5.2 & 6.1 & 8.0 \\
\hline 2003 & 7.9 & 13.6 & 9.1 & 19.1 \\
\hline 2004 & 10.8 & 14.2 & 15.8 & 21.8 \\
\hline 2005 & 4.5 & 5.0 & 6.9 & 18.8 \\
\hline Average & 6.5 & 9.5 & 9.5 & 16.9 \\
\hline
\end{tabular}

Table 3

Yearly and period average error value of capacity factor estimation for the Weibull distribution approach compared to the chronological approach

\begin{tabular}{lllc}
\hline & Entire year $(\%)$ & Strong wind period $(\%)$ & Weak wind period $(\%)$ \\
\hline 2002 & 3.5 & 3.4 & 3.5 \\
2003 & 8.8 & 6.1 & 11.5 \\
2004 & 7.0 & 4.4 & 9.5 \\
2005 & 6.5 & 2.5 & 10.6 \\
Average & 6.5 & 4.1 & 8.8 \\
\hline
\end{tabular}

$2.5-6.1 \%$ and $3.5-11.5 \%$, respectively, resulting in the 4-year averaged error values of $4.1 \%$ and $8.8 \%$, respectively. The PAEV in the weak wind period exceeds twice as much as that in the strong wind period. This result is possibly due to the fact that the Weibull distribution approach does not accurately represent the situations where the wind speeds are zero or close to zero.

\section{Conclusions}

Based on the monthly capacity factors calculated from the chronological and probabilistic approaches and the measured capacity factors obtained in the Mailiao wind power station, the present research has led to the following conclusions:

(1) For this location of Mailiao, it can be seen that the strong wind period is from October to March, in which the monthly capacity factors are between 0.24 and 0.69 , whereas the weak wind period is from April to September with the monthly capacity factors only ranging from 0.03 to 0.29 . The strong wind period leads to significantly higher capacity factors than the weak wind period.

(2) The YAEV in the years of 2002-2005 are calculated. Both approaches provide acceptable accuracy for estimating capacity factor. The 4-year averaged error value of the chronological approach is lower than that of the Weibull distribution approach.

(3) Both approaches slightly underestimate the capacity factors in the strong wind period. This underestimated error could result from the combined effect of the velocity-deficit error of the anemometer measurement and the error of using half-hourly time-series 
data. On the contrary, both approaches significantly overestimate the capacity factors in the weak wind period for the reason that using the lowest speed at which power can be produced as the definition of the cut-in speed in the turbine power curve would result in overestimated power output at low winds.

(4) The present study also investigates the differences between the two approaches. The result shows that the YAEV of the Weibull distribution approach is between $3.5 \%$ and $8.8 \%$. This result is similar to the research of Celik [12]. The PAEV in the weak wind period exceeds twice as much as that in the strong wind period, which is possibly due to that the Weibull distribution approach does not accurately represent the situations where the wind speeds are zero or close to zero.

\section{References}

[1] Burton T, Sharpe D, Jenkins N, Bossanyi E. Wind energy handbook. West Sussex, UK: Wiley; 2001.

[2] Chang TJ, Wu YT, Hsu HY, Chu CR, Liao CM. Assessment of wind characteristics and wind turbine characteristics in Taiwan. Renew Energy 2003;28:851-71.

[3] Jangamshetti SH, Rau VG. Site matching of wind turbine generators: a case study. IEEE Trans Energy Convers 1999;14(4):1537-43.

[4] Jangamshetti SH, Rau VG. Optimum siting of wind turbine generator. IEEE Trans Energy Convers 2001;16(1):8-13.

[5] Weisser D, Foxon TJ. Implications of seasonal and diurnal variations of wind velocity for power output estimation of a turbine: a case of Grenada. Int J Energy Res 2003;27:1165-79.

[6] Pallabazzer R. Previsional estimation of the energy output of windgenerator. Renew Energy 2004;29:413-20.

[7] Jaramillo OA, Borja MA. Wind speed analysis in La Ventosa, Mexco: a bimodal probability distribution case. Renew Energy 2004;29:1613-30.

[8] Celik AN. A statistical analysis of wind power density based on the Weibull and Rayleigh models at the southern region of Turkey. Renew Energy 2004;29:593-604.

[9] Akpinar EK, Akpinar S. A statistical analysis of wind speed data used in installation of wind energy conversion systems. Energy Convers Manage 2005;46:515-32.

[10] Akpinar EK, Akpinar S. An assessment on seasonal analysis of wind energy characteristics and wind turbine characteristics. Energy Convers Manage 2005;46:1848-67.

[11] Ramirez P, Carta JA. Influence of the data sampling interval in the estimation of the parameter of the Weibull wind speed probability density distribution: a case study. Energy Convers Manage 2005;46:2419-38.

[12] Celik AN. Energy output estimation for small-scale wind power generators using Weibull-representative wind data. J Wind Eng Ind Aerodyn 2003;91:693-707.

[13] Castro R, Ferreira L. Comparison between chronological and probabilistic methods to estimate wind power capacity credit. IEEE Trans Power Syst 2001;16(4):904-9.

[14] Al-Abbadi NM. Wind energy resource assessment for five locations in Saudi Arabia. Renew Energy 2005;30:1489-99.

[15] Sen Z. Stochastic wind energy calculation formulation. J Wind Eng Ind Aerodyn 2000;84:227-34.

[16] International Energy Agency. Recommended practices for wind-turbine testing and evaluation: 1. Power performance testing, 2nd ed. London: UK, DTI; 1999.

[17] Perez IA, Garcia MA, Sanchez ML, de Torre B. Analysis and parameterisation of wind profiles in the low atmosphere. Sol Energy 2005;78:809-21.

[18] Mayer C, Bechly ME, Hampsey M, Wood DH. The starting behaviour of a small horizontal-axis wind turbine. Renew Energy 2001;22:411-7.

[19] Wright AK, Wood DH. The starting and low wind behaviour of a small horizontal axis wind turbine. J Wind Eng Ind Aerodyn 2004;92:1265-79. 